\title{
Intergenerational Linkages in Consumption Behavior
}

\author{
Donald Cox $\quad$ Serena Ng Andreas Waldkirch
}

November 2000

\begin{abstract}
Consumption is partly a social activity, yet most studies of consumer behavior treat households in isolation. We investigate familial relationships in consumption patterns using a sample of parents and their children from the Panel Study of Income Dynamics. We find a positive and statistically significant parent-specific effect on children's consumption even after controlling for the effect of parental income, and we find similar effects for sibling pairs. Child consumption responds negatively to large post-retirement shortfalls in consumption of the parents. This behavior holds up even after allowing for the possibility of smaller parent-to-child transfers made necessary by the parental consumption shortfalls. These results suggest that although income is an important source of the intergenerational correlation, parental choices and experiences also affect consumption behavior of the children.
\end{abstract}

JEL Classification: D10, D12, E21, J26

Keywords: Family, income, tastes, retirement, learning.

This paper was presented at the 2000 World Congress of the Econometric Society, Vanderbilt University, and the consumption workshop at the University of Chicago. We would like to thank the seminar participants for their suggestions, and to Alwyn Young and Nicholas Souleles for helpful comments on an earlier draft. Correspondence: Serena Ng, Department of Economics, Boston College, Chestnut Hill, MA 02467. 


\section{Introduction}

It was once thought that economic mobility was high enough that the effects of any earnings innovations would be wiped out in three generations (Becker and Tomes [1986]). Since that study, there has been new evidence, based on longer panels of earnings, that intergenerational earnings mobility is less fluid than envisioned by Becker and Tomes. ${ }^{1}$ Economic stratification across generations is just as pronounced if we examine consumption data, arguably a more accurate measure of economic well-being. Only about 8 percent of the adult children with parents from the lowest consumption quintile make it into the highest quintile. ${ }^{2}$

But while most would agree that the intergenerational correlation in consumption is largely a manifestation of the correlation in earnings between generations, it is much less clear whether income is the only source of this correlation. This paper explores the possible role that preference and behavior might play in accounting for the intergenerational consumption correlation using information about parents and their children from the Panel Study of Income Dynamics (PSID). Our analysis consists of two parts. We first develop a model that allows both parental income and other parent specific effects unrelated to income to be transmitted from one generation to the next. The model is used to assess the relative importance of both parental effects in consumption of their children. We then look for evidence of cognitive behavior by examining whether children learn from their parents' retirement experiences.

The first part of the analysis is motivated by the fact that several studies have documented that patterns in consumption and wealth cannot be accounted for by the individual lifecycle model and commonly considered household characteristics. ${ }^{3}$ For example, why do the majority of consumers save so little, but a small number of them save a great deal? One reason could be that most economic models of consumption treat the household in isolation, even though there is good reason to believe that consumption is, at least partly, a social activity that likely extends beyond the confines of the nuclear family. Although allowing the family's budget to influence individuals' decisions is a natural extension to the standard model, there are other ways by which familial influence can arise. For example, children may strive to "keep up" with the consumption patterns of their parents and siblings, and their well being might depend in part on comparisons with these reference groups. Children might acquire consumption related habits early in life while they are still living with their

\footnotetext{
${ }^{1}$ See, for example, Behrman and Taubman (1990), Solon (1992), Zimmerman (1992), and Mulligan (1997).

${ }^{2}$ Evidence on consumption mobility will be presented in more detail in Table 1 below.

${ }^{3}$ See Lusardi (2000) for evidence from the Health and Retirement Survey. Browning and Lusardi (1997) provide a survey of savings and anomalies not explained by standard optimizing models of consumption.
} 
parents, and retain these habits after leaving home. They might learn their savings and investment behavior by watching their parents, or they might acquire an aversion to risk from their parents' inclinations or experiences. Allowing for such parental influences could explain some of the previously unexplained heterogeneity in consumption behavior. In the paper, we refer to all parental effects unrelated to income as "tastes". The basis of our empirical work is that if income were the sole source of correlation in consumption between generations, then familial tastes should be insignificant once parental income is taken into account.

The second part of the analysis is motivated by the fact that the way in which children perceive their parents' experience could be particularly important for one of the leading policy issues we currently face. Numerous studies have documented widespread shortfalls in consumption upon retirement (see Bernheim, Skinner and Weinberg (1997) and other references cited therein). One important and open question is whether this phenomenon is unique to the current generation of retirees, or whether future generations will repeat history and find themselves not saving enough as well. The answer depends partly on the extent to which the post-retirement change in parental consumption affects their childrens' behavior. On the one hand, if parental and child preferences and resources are correlated, the children might be fated to follow their parents' footsteps. On the other hand, children might learn from their parents' experience, and alter their behavior accordingly. We therefore exploit the parental retirement experience to see if there is any evidence for social learning.

Despite the potential importance of intergenerational influences for consumption and savings behavior, most of the literature on intergenerational relationships has focused on income or earnings. ${ }^{4}$ Furthermore, economists are only beginning to investigate intergenerational correlations in consumption. The two studies that we are aware of both find the parental correlation to be large and statistically significant. Chiteji and Stafford (1999) analyzed intergenerational relationship in portfolio choices and found intergenerational similarities in asset selection. But the authors confined their attention to bank accounts and stock ownership, and their primary focus was on racial differences in wealth accumulation. Mulligan (1997) controlled for life cycle and business cycle effects in consumption and finds the intergenerational correlation in time-averaged consumption to be quite large. However, it is not clear whether the correlation would remain significant once the correlation in parental income is taken into account, and this is the issue that we will take as the starting point. Indeed, the present paper appears to be the first to go beyond documenting the simple correlations in the data to explore the possibility that the intergenerational transmission might take place via

\footnotetext{
${ }^{4}$ Mulligan (1997) surveys many of the studies on income. See also Altonji and Dunn (1994).
} 
a channel other than income. The work (in progress) by Charles and Hurst (2000) is closest to ours in terms of motivation. These authors also look for evidence of intergenerational linkages beyond income, but they focus on wealth rather than consumption.

The plan of the paper is as follows. Section 2 contains a general discussion of why one might expect intergenerational correlations in consumption. The data used in the empirical work are described in Section 3. In Section 4, we estimate an intergenerational model that allows for transmissions via income and tastes. The model is then modified to study sibling effects. The results are reported in Section 5. Next, we investigate the idea that the behavior of children might change as a result of the experience of parents. Our results confirm an intergenerational transmission in consumption via earnings, but also suggest that children acquire the taste of their parents, and that they learn from their parents' experience.

\section{Possible Explanations for Intergenerational Correlations in Consumption}

Parent-child correlation in consumption can be consistent with a variety of channels of intergenerational influence. It could be the result of parents' efforts to modify their children's behavior. In Becker and Mulligan (1997), for example, parents devote resources to reducing their childrens' subjective rate of time preference. Thus, rich people, or people with rich parents, 'choose' to be more patient. Furthermore, wealthier parents have greater capacity for undertaking productive human capital investments in their children. Consumption between generations could be correlated to the extent that such investments lead to higher permanent income.

Similarities in consumption behavior between generations could also arise even if parents do not actively influence the behavior of their children. As outlined in Becker and Tomes (1986) and discussed in Behrman and Taubman (1990), a parent who is especially talented will have a higher-than-average demand for her human capital and hence earnings. Her child is also likely to be similarly talented (though not identically so if talent regresses to the mean) so that his demand curve for human capital and earnings will also be higher than average. Correlations in human capital will generate intergenerational correlations in permanent incomes, and hence consumption.

A parent-child correlation in consumption could also arise from the unintentional transmission of parental preference to children. Such preferences could be intratemporal, as in the case where children acquire his parents' taste for sports cars and for dining out. The

preferences could also be intertemporal, as in cases where children observe their parents being thrifty. Children may also acquire a taste for saving when parents encourage them 
to put money into their piggy banks. Parents who enjoy gambling might unintentionally pass on to their children an affinity for risk taking. Children might develop an interest for investing in the stock market as a result of nightly discussions at the dinner table. Two generations with similar rates of time preference and degrees of risk aversion would then have similarly sloped age-consumption profiles. Family medical history might lead to special awareness for precautionary saving. Heritability of life-span could, at least in principle, generate intergenerational correlations in consumption as well.

Consumption externalities such as the ones discussed in the early literature on the relative income hypothesis (Duesenberry [1949]) or the literature on bandwagon and snob effects (Leibenstein [1950]), can also generate intergenerational correlations in consumption. Suppose the consumer's utility is given by $U\left(C_{t}, S_{t}\right)=u\left(C_{t}-\beta S_{t}\right)$. If the reference variable $S_{t}$ is taken as aggregate consumption, then the model is what Abel (1990) referred to as 'keeping up with the Joneses'. But it seems just as reasonable to suppose that children might use the consumption of their parents or siblings rather than the average consumer as the reference group. Following the literature, we refer to this type of 'keeping up with their parents' behavior as an "external habit". It is a form of deliberate imitation, since what is being imitated is the parents' consumption or standard of living.

Suppose habits follow the law of motion, $S_{k, t}=\left(1-\theta_{k}\right) S_{k, t-1}+C_{k, t}$, where the subscript $k$ denotes child variables. Now instead of the common practice of taking the initial condition $S_{k, 0}$ as exogenously determined, think of $S_{k, 0}$ as the level of habit that the child inherits from his parents during the years of co-residence. That is, $S_{k, 0} \propto C_{p}$, where $C_{p}$ is permanent consumption of the parent. Although the importance of the initial habit falls at rate $\theta_{k}$ as the child ages, parental habits will be passed on to their children via $S_{k, 0}$. Notice that this effect of the initial habit is obtained whether habits are internal or external to the consumer. We refer to this as the "inherited habit" effect. ${ }^{5}$

The channels discussed above suggest several reasons to expect positive correlations in consumption. Are there other channels that might lead to correlations in the opposite direction? The shared budget constraints hypothesis of Becker and Tomes (1986) indeed makes such a prediction. To see why this is the case, let $Y_{p}$ denote the permanent income of the parent, and $C_{p}$ denote the present discounted value of her consumption, and variables for the child, $Y_{k}$ and $C_{k}$, are similarly defined. Suppose households are altruistic. The shared budget constraint implies that $C_{k}=Y_{k}+Y_{p}-C_{p}$. With permanent incomes constant, the less my parents consume, the more resources are left over for me, leading to a negative correlation in consumption. One might dismiss this prediction because such an extreme implication for

\footnotetext{
${ }^{5}$ The effect of parental habits is to be investigated in a separate paper by the authors.
} 
consumption implied by the altruism model was rejected by Altonji, Hayashi and Kotlikoff (1992). But suppose the motive for intergenerational transfers is exchange, such as discussed in Bernheim, Shleifer and Summers (1985) or Cox (1987). According to the exchange view, my parents might amass a large estate, or make frequent inter-vivos transfers, to elicit "child services." The excess of $Y_{p}$ over $C_{p}$ is then used to make transfers to the child. With parental income constant, an increase in parental consumption should also reduce child consumption. Either motive for transfers thus predicts the same negative intergenerational correlation in consumption, controlling for permanent incomes.

Although intergenerational correlations in consumption can arise for reasons discussed above, and trying to identify these causes is no small task, it is also possible that we will not observe such correlations in the data. Becker and Tomes discussed a number of reasons why consumption might still regress to the mean. For example, if parents cannot exact transfers from their children, positive innovations in child earnings will not be met with increased transfers from children to parents. Other factors include the effects of uncertainty, the influence of wealth on fertility and assortive marriage markets (Becker and Tomes [1986, p. S21]). Mulligan (1997) argues that endogenous parental altruism can also cause consumption to regress to the mean, since rich parents who have high opportunity costs might spend less time with their children.

Two other factors could also override familial influences. The first is liquidity constraints, since consumption behavior is then controlled by the scarcity of financial wealth in spite of any desire to catch up with or imitate parents. This suggests that intergenerational correlations in consumption should be weaker for the poor than for the rich. The second is the duration of co-residence, as the shorter the duration, the less frequent will children

have the opportunity to imitate and acquire the habits of their parents. Depending on the importance of these factors in the data set under investigation, intergenerational correlations in consumption could be weak. Ultimately, whether economists should care if there are intergenerational correlations in consumption depends on the significance of this correlation in the data. We now turn to the PSID sample to assess its importance of this correlation.

\section{The PSID Data, Splitoffs and Data Description}

Our data come from the Panel Study of Income Dynamics (PSID), a longitudinal survey of U.S. individuals and their families. Heads and spouses of households are re-interviewed each year, starting in 1968. We refer to this sample of earliest parents as "main households." In addition, if main household members leave to form households of their own, they are 
followed and interviewed as well. This occurs not only in the case of divorce or separation, but also in the case in which children leave home to set up their own households, henceforth referred to as child splitoffs, or simply splitoffs. Thus, the PSID has grown over the years from an initial sample of about 4,800 households to nearly 10,000 in 1992, the last year of our sample. ${ }^{6}$

Because we want to measure intergenerational relationships, we follow Altonji, Hayashi and Kotlikoff (1992) and construct a data set of parental and splitoff households that satisfies the following three conditions: i) the parents must be respondents in the first wave of the PSID in 1968; ii) the child splitoffs must have been recorded as children of those earliest parents, and iii) the child must have left the parental household sometime between 1969 and 1992. Table A in the Appendix contains selected summary statistics from the resulting data file. There are 842 main households and 1,808 splitoff households - a little over 2 splitoffs per main household. The average main household head was 62.9 years old in 1992, and by that year 40.9 percent of them had retired. ${ }^{7}$ The average age of the splitoffs is 35 , and the average age at which they left home is 22.9 .

Income data are available in all waves of the PSID. Income refers to the previous year, so that our income data range from 1967 to 1991. Questions about consumption were asked in all years except 1973, 1988 and 1989. We also cannot use information for 1968 because the question about food consumed outside the home was asked starting in 1969. Following prevailing conventions, we let consumption information refer to the year in which the question was asked. After deleting those main households with missing information for some of the years, the average number of years for which there are usable consumption observations is 20.9. Of these years, an average of 2.77 years are spent in retirement. For the splitoff households we have, on average, 11.26 years of consumption information.

We focus on two consumption measures in the empirical work: total food, and what is referred to below as "Skinner consumption". The latter, based on Skinner (1987), combines information related to food and non-food consumption indicators from the PSID with information from the Consumer Expenditure Survey (CEX) for 1983 in order to impute a broader measure of consumption. The PSID also measures separately expenditures for food consumed inside and outside the home, which we exploit later to analyze intergenerational correlations in the composition of consumption.

Table 1 reports the intergenerational mobility in the distribution of income and Skinner's

\footnotetext{
${ }^{6}$ The PSID samples households from a "representative" sample and a special "low-income" sample. We consider only the representative sample, and we treat it as self-weighting. We also do not include the additional Latino sample that was added in 1990.

${ }^{7}$ The definition of retirement will be explained in the next section.
} 
consumption averaged over time. The consumption distribution matches up fairly closely with the income distribution, and is perhaps even more stratified. The table reinforces the findings of other studies indicating that average economic well-being (as opposed to economic well-being measured at a point in time) is highly stratified across generations. Nearly 40 percent of the children in the lowest quintile of time-averaged consumption have parents who were also in the lowest quintile. And a little over 40 percent of the children in the highest quintile came from main households who were also in the highest consumption quintile. In contrast, only about 8 percent of the children growing up in main households from the lowest consumption quintile made it into the highest consumption quintile after leaving home. If we regress average consumption of the children on the average consumption of the parents, the estimated coefficient is 0.43 , and strongly significant. Thus, crude evidence for intergenerational correlation in consumption appears quite compelling. But such simple statistics do not give any indication about the source of this correlation. In the next section, we go beyond this simple correlation to a model that puts more structure on the intergenerational transmission.

\section{An Econometric Model of Intergenerational Linkages}

As discussed earlier, parent and child behavior could be intergenerationally linked not because of tastes per se, but because income is intergenerationally linked. Numerous studies have demonstrated that income and wealth are positively correlated across generations. This section presents a framework which allows for intergenerational correlations in both income and tastes. Altonji and Dunn (1994) used a similar framework to study the intergenerational correlation in earnings and labor supply.

We begin by setting up some notation. Main households are indexed by $i=1, \ldots, N$. The $i^{\text {th }}$ main household has $K_{i}>0$ children. Let $x_{i 0, t}$ be the value of the variable $x$ for the main household $i$ at time $t$, and $x_{i j, t}, j=1, \ldots K_{i}$ be the value of $x$ for the $j^{\text {th }}$ splitoff associated with main household $i$.

We assume that (log) consumption and (log) income are determined by four factors: life cycle effects; business cycle effects; individual-specific time-invariant effects; and individualspecific random effects. We are interested in the intergenerational correlation in the individualspecific effects that are time invariant. As in Altonji, Hayashi and Kotlikoff (1992), we first regress the log of consumption and the log of income of the main households and the splitoffs on life cycle variables (age, age-squared, family size, marital status, a female head and a retirement dummy) and business cycle variables (an unemployment dummy and year 
dummies). These auxiliary regressions yield corresponding consumption and income residuals that are orthogonal to business cycle and life-cycle effects. Denote these residuals by $c_{i 0, t}, c_{i j, t}, y_{i 0, t}$, and $y_{i j, t}$. Hereafter, we simply refer to these variables as "consumption" and "income". Our objective is to see if $c_{i 0, t}$ and $c_{i j, t}$ are correlated after allowing for intergenerational correlations in income.

Our intergenerational model is specified by i) an income process for the parents, ii) an income process for the splitoffs, iii) a consumption function for parents, iv) a consumption function for children, $v$ ) an intergenerational transmission of income, and vi) an intergenerational transmission for tastes.

Income We model observed income as follows:

$$
\begin{aligned}
& y_{i 0, t}=y_{i 0}+z_{i 0, t}, \\
& y_{i j, t}=y_{i j}+z_{i j, t} .
\end{aligned}
$$

The variables $y_{i 0}$ and $y_{i j}$ are person-specific intercepts of income which we simply refer to as permanent income. One can think of these as time averages of income. The dynamics of income are captured by $z_{i 0, t}$ and $z_{i j, t}$. We model these as $\operatorname{ARMA}(1,1)$ processes and allow the autoregressive and moving average parameters to be generation specific, viz:

$$
\begin{aligned}
& z_{i 0, t}=\rho_{0} z_{i 0, t-1}+\epsilon_{i 0, t}+\theta_{0} \epsilon_{i 0, t-1} \\
& z_{i j, t}=\rho_{1} z_{i j, t-1}+\epsilon_{i j, t}+\theta_{j} \epsilon_{i j, t-1}
\end{aligned}
$$

Consumption We posit that consumption has a predictable component and a transitory component. The predictable component can be further decomposed into permanent income and taste components. In our analysis, tastes is a catch-all term for all household specific effects unrelated to income. Denoting tastes of the main households and the splitoffs by $d_{i 0}$ and $d_{i j}$ respectively, we have:

$$
\begin{aligned}
c_{i 0, t} & =a y_{i 0}+d_{i 0}+e_{i 0, t}, \\
c_{i j, t} & =b y_{i j}+d_{i j}+e_{i j, t},
\end{aligned}
$$

where $e_{i 0 t}$ and $e_{i j, t}$ are the mean zero idiosyncratic and serially uncorrelated innovations in consumption. $^{8}$

\footnotetext{
${ }^{8}$ The preferred model is to specify consumption as a function of both permanent income and assets. Unfortunately, information on assets is available for 1984 and 1989 only.
} 
Intergenerational Linkages There are two intergenerational transmission mechanisms: income, and tastes. We assume that permanent income of the splitoffs has a component under parental influence, and one that is purely individual specific. That is,

$$
y_{i j}=\phi y_{i 0}+u_{i j}
$$

where $u_{i j}$ is the component of permanent income that is child-specific. The parameter $\phi$ is the elasticity of the permanent income of the splitoffs with respect to parental permanent income and summarizes the effect of the intergenerational transmission of income. Analogously, the transmission of tastes is specified as:

$$
d_{i j}=\gamma d_{i 0}+v_{i j}
$$

where $v_{i j}$ is the child-specific component of taste. The parameter $\gamma$ summarizes the intergenerational transmission of tastes. Notice that if tastes are transmitted from parents to children, then tastes of siblings would also be correlated.

For identification purposes, we impose the restrictions that i) transitory consumption is uncorrelated with the innovations in income (both in the time and the cross section dimension e.g. $\left.\operatorname{cov}\left[e_{i 0, t}, \epsilon_{i j, s}\right]=0 \forall i, j, t, s\right)$; ii) permanent income and tastes are uncorrelated with transitory income and consumption (also in the time and cross-section dimension, e.g. $\left.\operatorname{cov}\left[y_{i 0}, e_{i o, t}\right]=0 \forall t\right)$, and $\left.i i i\right)$ tastes and permanent income are orthogonal. In principle, rich people may have rich tastes, but there is nothing in the model to tie down this correlation. We initially iterated on the correlation between permanent income and taste and found the values that minimize the objective function to be generally very small (and contrary to our prior the values are negative, in the -.1 to -.2 range). We simply impose $\operatorname{cov}\left[y_{i 0}, d_{i 0}\right]=0$ and $\operatorname{cov}\left[u_{i j}, v_{i j}\right]=0$. The assumption allows us to interpret $\gamma$ as a measure of the extent to which there remains an intergenerational correlation in consumption, after controlling for the parent-child correlation in income. If $\gamma$ is zero, the parent-child relationship in consumption is just driven by income considerations with little room for intergenerational correlation in tastes. After imposing all the restrictions, the parameters to be determined are $a, b, \phi, \gamma$, $\operatorname{var}\left[d_{i 0}\right], \operatorname{var}\left[d_{i j}\right], \operatorname{var}\left[y_{i 0}\right], \operatorname{var}\left[y_{i j}\right], \operatorname{var}\left[\epsilon_{i 0 t}\right], \operatorname{var}\left[\epsilon_{i j t}\right], \operatorname{var}\left[e_{i 0 t}\right], \operatorname{var}\left[e_{i j t}\right], \theta_{0}, \theta_{1}, \rho_{0}$, and $\rho_{1}$.

Equations (1), (2), (3) and (4) define the model. Consumption of the splitoffs can be written as

$$
c_{i j, t}=b \phi y_{i 0}+\gamma d_{i 0}+b u_{i j}+v_{i j}+e_{i j t}
$$

so there are two parent-related components and three splitoff-specific components of consumption. In most empirical studies, time invariant effects are not the objects of interest. 
However, the focus of the present study is precisely to see if the parent-specific effects are correlated with the splitoff-specific effects. One possibility is to separately perform fixed effect estimation of (2) and (5), and then correlate the estimated fixed effect of the parents with the estimated fixed effect of the splitoffs. However, because little is known about the statistical properties of the correlation coefficient taken between two fitted series, inference cannot be made about the significance of the intergenerational correlation. An additional problem is that this procedure does not allow us to decompose the parental effect into an income component and one that is uncorrelated with income.

We therefore adopt an alternative estimation strategy. Following Altonji and Dunn (1994), we exploit the covariance structure of the model to generate a set of moments, and the parameters are estimated by minimizing the difference between the second moments implied by the model and the data. More precisely, taking expectations of the cross-products of consumption and income yields population second moments defined in terms of the unknown parameters of the model. Assuming that the second moments are time invariant, there are ten contemporaneous covariances that exist among the variables $c_{i 0 t}, c_{i j t}, y_{i 0 t}$ and $y_{i j t}$. For each lag, there are sixteen autocovariances. We exploit information up to the second lag in the estimation and therefore have a total of 42 moments. These are given in Appendix B. The sixteen parameters are estimated by matching the moments implied by the model to the corresponding 42 population moments, which can be consistently estimated by their sample analogs. Because of missing observations and the non-balanced nature of the panel, the sample used to compute the empirical moments changes with the moment in question. The sample size for the splitoffs is generally larger than for the main households for a given $t$ because each main household can have more than one splitoff. However, data for the splitoffs are available over a shorter span. In consequence, more observations are used to calculate the sample moments for the main households than for the splitoffs.

Let $D_{j}$ be the difference between the $j^{\text {th }}$ observed moment and the corresponding model implied moment. If the model is correctly specified, the stacked $42 \times 1$ vector $D$ should have mean zero. The parameters can be consistently estimated by minimizing the objective function $D^{\prime} \Omega D$, where $\Omega$ is a weighting matrix. The choice of $\Omega$ affects the efficiency of the estimates. As discussed in Altonji and Segal (1996) and Altonji and Dunn (1994), use of the optimal weighting matrix could lead to large finite sample bias in the parameters estimates. Following Abowd and Card (1989) and Altonji and Dunn (1994), we use weighting matrices that do not depend on the parameter estimates. We consider two choices of $\Omega$ : an identity matrix, and the inverse of the sample variance of the second moments. The identity matrix weighs the moments equally and the results will be referred to as the equally weighted 
estimates. The inverse of the variances perform unequal weighting of the moments and will be referred to as weighted least squares. The two sets of results are quite similar in all but one case which will be noted below. To conserve space, we concentrate on the results for equally weighted estimates (which tend to have larger standard errors).

\section{Results}

In this section, we first present our main results concerning the level of consumption. This is followed by an analysis of the composition of consumption. An implication of our model is that if tastes are correlated between parents and their children, then the tastes of siblings might also be correlated. We therefore examine if sibling effects are present in the data. The robustness of the results to the treatment of retirement is then investigated.

\subsection{The Level of Consumption}

The question that most interests us is the importance of parental effects on consumption of the splitoffs. In our model, the intergenerational transmission of permanent income is captured by the parameter $\phi$, and the transmission of parental tastes is summarized by $\gamma$. Table 2 reports what we refer to as "base case" results. These are equally weighted estimates (i.e. with $\Omega=I$ ), based on data that include only those splitoffs for whom we have at least ten years of data. Using Skinner's definition of consumption, we obtain a point estimate for $\phi$ of .479 , with a standard error of $.015 .^{9}$ Income is therefore transmitted intergenerationally. The statistical significance of $\phi$ is perhaps not surprising, given the well-documented evidence on the stratification of income. The new and striking result is that the effect of parental tastes, as summarized by $\gamma$, has a point estimate of .339 with a standard error of .048. Thus, there is a statistically significant correlation in tastes for consumption between generations. These findings on $\phi$ and $\gamma$ imply that consumption is not an isolated activity. Not only does parental income affect consumption of the splitoffs, the effect of parental tastes is found in the data even after parental income is taken into account.

The parameters $a$ and $b$ represent the propensities to consume out of permanent income. These are estimated to be .850 for the main households and .871 for the splitoffs, both with tight standard errors. Our ARMA(1,1) estimates are .794 and -.314 for the main households (with standard errors of .028 and .054), and .629 and -.290 for the splitoffs (with standard

\footnotetext{
${ }^{9}$ This is in line with estimates e.g. by Behrman and Taubman (1990), Solon (1992), and Zimmerman (1992).
} 
errors of .053 and .069) respectively. ${ }^{10}$ Thus, introducing the two parental effects and allowing for joint estimation of the specifications for consumption and income still give reasonable estimates of the income dynamics and the propensities to consume.

Although the estimates for $\phi$ and $\gamma$ are statistically well determined, this does not imply that the effects of parental income and tastes are quantitatively important. This is because the variance of parental tastes and income also matters. The lower panel of Table 2 provides various decompositions to assess the importance of the parental variables. Evaluated at the base case estimates, .126 of the variation in tastes of the splitoffs is transmitted from parents, and .200 of the variation in permanent income of the splitoffs is influenced by parental income. Not surprisingly, the parental income effect is larger than the parental taste effect, but the parental taste effect is clearly statistically significant and remains non-negligible even after parental income is taken into account. The combined parental effect accounts for 14 percent of the total variance of the splitoffs' consumption and about 24 percent of the variation that is predictable. These results support the presence of intergenerational linkages in consumption.

Results for total food consumption are reported in the second column of Table 2. The income dynamics are estimated to be similar to those in column 1 for Skinner's consumption. The propensity to consume out of food is .588, smaller than for total consumption. As far as the key parameters are concerned, the data on food consumption also suggest the presence of a significant parental taste effect, even after parental income is taken into account. The point estimate for $\phi$ is .450, while that for $\gamma$ is .200. Both are smaller than the ones estimated using Skinner's consumption. Evaluated at the parameter estimates, parental income accounts for 6.7 percent of the variance of child's income, and parental tastes account for 4.3 percent of the child's taste. To the extent that a good part of food consumption arises as a result of need, it is possible that parental influence is stronger on those components of consumption on which the splitoffs have more discretion.

To check the sensitivity of the results, we re-estimated the model with a number of modifications made to the base case. Since the results generally present the same picture, we only report additional results for Skinner's definition of consumption. Column 1 of Table 3 are estimates obtained after outliers are removed from the sample. ${ }^{11}$ Apart from a smaller point estimate for $\phi$, the results are qualitatively and quantitatively similar to those of the base case. The results in column 2 are based on data of all the splitoffs, not just those with at least ten years of data. Again, the results are similar to the base case. In column 3 of

\footnotetext{
${ }^{10}$ Baker (1997) estimated a more general model for income and obtains autoregressive and moving average parameter estimates of .519 and -.187, respectively, with standard errors of .114 and .097.

${ }^{11}$ We removed splitoff families whose average income falls into the top or bottom 2.5 percent of the distribution. Neither this, nor other simple sample selection rules had any appreciable effect on the results.
} 
Table 3, we report estimates using weighted least squares, that is, estimates that use the inverse of the variance of the moments as the weighting matrix. The point estimate of $\gamma$ is smaller (.263 compared to .339) but remains statistically significant. With all three sets of alternative estimates, parental tastes explain 10 to 15 percent of tastes of the splitoffs, similar to the base case. ${ }^{12}$ The main result that parental effects are significant even after controlling for income is robust.

\subsection{The Composition of Consumption}

One implication of the intergenerational transmission of tastes is that there may be similarities in the composition of consumption between parents and the splitoffs. The PSID distinguishes between food consumed inside versus outside the home. If we view food consumed at home as a necessary good and food consumed outside home as a luxury treat, then spending on the two food components is the outcome of an intratemporal decision. This subsection exploits this information by investigating intergenerational correlations in the composition of consumption. We refer to the ratio of food consumed outside home to total food consumption as the food-out ratio. On average, this ratio is .17 for main households, and .26 for the splitoffs, with a simple correlation between generations of 0.15 .

We re-estimate the intergenerational model with $c_{i 0 t}$ and $c_{i j t}$ now defined as the food out ratio (again, controlling for life-cycle and business cycle effects). The results are presented in the third column of Table 2. The intergenerational transmission of permanent income, $\phi$, is .513. The taste parameter $\gamma$ is 0.12 and statistically different from zero, but is somewhat lower than the simple correlation of 0.15. At face value, a one percent increase in parental tastes for food outside home will increase the splitoff's taste for eating out by .12 of one percent. However, two-thirds of the variation in the food-out ratio of splitoffs is transitory, while the rest is mainly is due to their own tastes. Parental income and tastes combined account for 1.1 percent of the variation in the food-out ratio. We thus conclude that although both parental influences are statistically significant, neither is quantitatively important for determining the composition of consumption of the splitoffs.

\subsection{Sibling Effects}

Sibling correlations in tastes could arise because they grow up under the same parental influence, or because years of co-residence create opportunities for imitation of habits and tastes. To study correlations in siblings' consumption, we use the same framework laid out

\footnotetext{
${ }^{12}$ We also tried allowing for serial correlation in transitory consumption. The serial correlation parameters are significant, though numerically small. The estimates for $\gamma$ are similar and remain strongly significant.
} 
in Section 2, with two definitional changes. In this subsection, $x_{i 0 t}$ is the value of $x$ for the first-born of the main household $i$ at time $t$, and we only consider those $x_{i j t}$ with $j>1$. This amounts to using the first-born splitoff as the reference household. Thus, if main household $i$ has $K_{i}>1$ children, we effectively examine the correlation in consumption between $c_{i 1 t}$ and $c_{i j t}$ for $j=2, \ldots K_{i}$. We refer to this as the intragenerational model. If sibling behavior is correlated only because the behavior of each is correlated with the parents, then the choice of the reference sibling is irrelevant. However, by virtue of birth order, the behavior of the first born is more likely to be learned by the younger siblings. Of the 1,808 splitoff households, 332 were the only splitoff and cannot therefore be used for this part of the analysis. After dropping these households we are left with 510 oldest siblings and their 966 younger siblings who have formed their own households as well. ${ }^{13}$

The parameter estimates for the intragenerational model are reported in Table 4. Because the time dimension of the sample is small, the estimates are generally less precise than those in Table $2 .{ }^{14}$ In all three models, the sibling-permanent income effect, $\phi$, is estimated to be roughly the same as the parental permanent income effect reported in Table 2. Permanent income of the oldest sibling explains 17 percent of the variance in permanent income of other siblings, also similar in magnitude to the parental effect. However, the intragenerational taste effect appears larger than the intergenerational effect. Using Skinner's consumption, $\gamma$ is now .453, and tastes of the oldest sibling now accounts for close to 30 percent of the taste of the younger siblings. The results thus suggest the presence of intragenerational linkages in consumption.

\subsection{Controlling for Retirement Effects and an Overview}

Retirement marks an important milestone of one's life cycle, and economists are still trying to understand the behavioral changes brought about by this one time event. So far, we have used a dummy variable to control for individual retirement. But retirement might affect the entire family, not just those who leave the labor force. To control for this effect, we add a parental retirement dummy to the first step regression of the splitoffs. The model for the entire sample is then re-estimated. Column 1 of Table 5 presents the results. All the estimates, including $\phi$ and $\gamma$, are very similar to the base case reported in Table 2. Still, the sample of splitoffs who see their parents retire at some point during the sample may

\footnotetext{
${ }^{13}$ In 34 cases there were two-way ties (and in two cases three-way ties) for the oldest sibling, and we designated the splitoff who left home first as the "oldest" sibling.

${ }^{14}$ Indeed, the estimated value of $v a r\left[v_{i j}\right]$ for Skinner's consumption is negative if the identity matrix is used. Thus, for column 1 of Table 4, the estimates are based on the optimal weighting matrix.
} 
exhibit behavior that differs from splitoffs that never have this experience. Thus we split the sample after the first stage regression and separately estimate the model for those whose parents never retire during the sample period ("Never retire", column 2) and those families whose parents retire at some point ("Retire", column 3). The point estimates for $\phi$ and $\gamma$ are unchanged. Our results thus appear robust to the treatment of retirement.

The model considered thus far has focused on isolating the average effects of the parental variables on consumption of the splitoffs. The main finding is that both parental income and tastes have statistically significant effects on consumption of the splitoffs. Evidently, the finding on income is consistent with Becker's investment view of human capital and reinforces the importance of income as a channel of intergenerational transmission. The finding concerning parental tastes is consistent with the view that splitoffs imitate their parents or unintentionally acquire their habits. In the next section, we will use the parental retirement experience to some light on another potential intergenerational linkage, namely, that children learn from the experience of their parents.

\section{Parental Retirement and Children's Consumption}

In this section, we turn our attention to whether there are adjustments in the consumption of the splitoff households after their parents retire. Hamermesh (1984), Mariger (1987) and Bernheim, Skinner and Weinberg (1997), among others, have reported evidence of widespread, large declines in consumption upon retirement. The observed reductions in consumption do not appear to be related to changes in work-related expenses or substitution of home for market production. That households do not save enough to prepare for retirement is mysterious, at least from the perspective of standard life-cycle theories of consumption. Understanding how children respond is important because the consumption shortfall problem would compound if such patterns tend to be repeated intergenerationally. Though retirement-related consumption shortfalls have attracted recent attention, no one has explored the possibility that such shortfalls affect the consumption behavior of children.

\subsection{The Retirement Sample}

We follow Bernheim, Skinner and Weinberg (1997) and mark the retirement date as the year in which neither the head nor spouse works more than 500 hours annually. If this pattern is sustained until the end of the sample period, the household is considered to have retired. Hereafter, we denote main household $i$ 's retirement year by $Y R_{i}$. Because the PSID started a long time ago, over a third of the main households had retired by 1992, the end of our sample 
period. We dropped those who retired so early in the panel that we could not measure preretirement consumption, and those who retired young (before 55). We are left with a sample of 281 main households for whom we can compare consumption before and after retirement. They are observed for an average of 16.9 years before retirement and 8.1 years afterward (see Table A). These main households are associated with 534 splitoff households, for whom we have an average of nearly 14 years of usable consumption observations:- 8.5 years of consumption information prior to parental retirement, and 5.4 afterward. The splitoffs were on average 39.4 years old in 1992 .

We are interested in how parental retirement-related consumption changes affect consumption of the splitoffs. For this purpose, define by Short $t_{i}$ the shortfall in consumption experienced by main household $i$ after retirement. The variable is constructed as follows. First, in order to restrict attention to the years that are not too distant from the year of retirement, we focus on parental consumption that occurred at most 10 years prior to $Y R_{i}$. Second, to avoid including consumption from years in which temporary shortfalls might occur from, say, unemployment, we restrict our attention to the pre-retirement years when at least one of the parents was working full time (i.e. 1500 hours or more). Let $\left\{w o r k_{i}\right\}$ be the set of years in which main household $i$ and/or his spouse has worked full-time in the last 10 years that data on pre-retirement consumption was available. Let $\left\{\right.$ retire $\left._{i}\right\}$ be the set of years between main household $i$ 's retirement and 1992, and that consumption data was available. Then nwork $_{i}$ and nretire $_{i}$ are the number of observations in $\left\{\right.$ work $\left._{i}\right\}$ and $\left\{\right.$ retire $\left._{i}\right\}$, respectively. The average of parental pre-retirement and post-retirement consumption are $C_{i 0}^{\text {pre }}=\frac{1}{\text { nwork }_{i}} \sum_{\tau \in \text { work }} C_{i 0, \tau}$ and $C_{i 0}^{\text {post }}=\frac{1}{\text { nret }_{i}} \sum_{\tau \in \text { retire }} C_{i 0, \tau}$, respectively. Our measure of post-retirement shortfall in consumption, denoted Short $_{i}$ is

$$
\text { Short }_{i}=-\left[\frac{C_{i 0}^{\text {post }}-C_{i 0}^{\text {pre }}}{C_{i 0}^{\text {post }}}\right] .
$$

Notice the minus sign used in the definition, so that a positive value indicates a shortfall.

The average value of Short $_{i}$ for our sample of main households was .123, and the median value was a shortfall of .159 percent. Nearly three-quarters (71.9 percent) of the 281 households experienced a post-retirement reduction in consumption (see Table A). These figures are consistent with those from other studies, which generally indicate large and widespread post-retirement consumption shortfalls.

\subsection{Results}

Let $X_{i j t}$ be variables that control for the life-cycle and business cycle effects of consumption, (i.e. age, age-squared, family size, marital status, a female head, a retirement dummy, 
an unemployment dummy and year dummies). Individual specific effects of consumption unrelated to parental retirement are summarized by a splitoff specific intercept $g_{i j}$, and will be controlled for by use of the fixed-effect estimator. ${ }^{15}$ In this way, differences in permanent income of the splitoffs will also be taken into account. We consider a number of specifications with increasing details about retirement. All the results are presented in Table 6. The simplest regression is:

$$
\log C_{i j, t}=g_{i j}+\delta_{0}+\delta_{1} D_{i, t}^{R E T}+\beta^{\prime} X_{i j, t}+e_{i j, t}
$$

where the parental retirement dummy, $D_{i, t}^{R E T}=1$ if $\left(t>Y R_{i}\right)$, and 0 otherwise. Using Skinner's measure of consumption, the point estimate for $\delta_{1}$ is -.014 and not statistically significant. Thus, consumption of the splitoffs does not seem to be affected by parental retirement per se. However, if we flag those observations associated with retired parents who experienced a positive shortfall in post-retirement consumption, parental retirement does seem to have an effect. Let $D_{i}^{\text {Short }}=1$ if Short $_{i}>0$ and zero otherwise. Consider

$$
\log C_{i j, t}=g_{i j}+\delta_{0}+\delta_{1} D_{i, t}^{R E T}+\delta_{2}\left[D_{i}^{S h o r t+} \cdot D_{i, t}^{R E T}\right]+\beta^{\prime} X_{i j, t}+e_{i j, t} .
$$

The coefficient on the interaction dummy measures the difference in consumption between those whose parents experienced a positive shortfall and those who did not. The point estimate of $\delta_{2}$ is -.064 and is significant at the $1 \%$ level. Unpleasant parental retirement experiences do seem to affect consumption of the splitoffs.

Our main interest is in the marginal effect of parental shortfalls on consumption of the splitoffs. By interacting the retirement dummy with the shortfall variable, the parameter $\alpha_{0}$ in the regression

$$
\log C_{i j, t}=g_{i j}+\delta_{0}+\alpha_{0}\left[\operatorname{Short}_{i} \cdot D_{i, t}^{R E T}\right]+\beta^{\prime} X_{i j, t}+e_{i j, t}
$$

summarizes this effect. The point estimate for $\alpha_{0}$ suggests that for the sample as a whole, a one percent increase in parental shortfall reduces consumption of the splitoffs by .152 of one percent, and the effect is statistically significant.

Since there are large variations in the shortfall variable, the marginal response of the splitoffs might depend on the size of the shortfall. We therefore consider a piecewise linear regression with quartile specific intercepts and slope responses to Short $_{i} .{ }^{16}$ We first calculate for each splitoff the quartile to which the shortfall of his parents belongs. From these, new

\footnotetext{
${ }^{15}$ The variable $g_{i j}$ can be thought of as $b \phi y_{i 0}+b \mu_{i j}+\gamma d_{i 0}+v_{i j}$ in the notation of the previous section.

${ }^{16}$ The control group consists of those whose parents have not retired.
} 
dummies, $D_{i, t}^{\text {Quartile }}(k), k=1, \ldots 4$, are created. These dummies take on a value of 1 if the shortfall of main household $i$ is in the $k^{\text {th }}$ quartile, and main household $i$ has retired at time $t$. The regression is:

$$
\log C_{i j, t}=g_{i j}+\delta_{0}+\sum_{k=1}^{4} \delta_{k} D_{i, t}^{Q u a r t i l e}(k)+\sum_{k=1}^{4} \alpha_{k}\left[\operatorname{Short}_{i} \cdot D_{i, t}^{\text {Quartile }}(k)\right]+\beta^{\prime} X_{i j, t}+e_{i j, t}
$$

where the $\delta_{k}$ coefficients are constrained so that the regression function is continuous at the three knotpoints of the shortfall variable. Then $\alpha_{k}$ is the response of $\log C_{i j, t}$ to his parent's shortfall, conditional on main household $i$ having retired, and that his shortfall is in the $k^{\text {th }}$ quartile. The point estimate for $\alpha_{4}$ is -1.129 with a standard error of .161. In contrast, the responses of those whose parents have smaller shortfalls are smaller and not significant.

We also estimated the equations using total food consumption as defined in the PSID. Surprisingly, the average shortfall in food consumption is .218, higher than for Skinner's consumption. The point estimate for $\alpha_{4}$ of -.987 with a small standard error. Furthermore, $\hat{\alpha}_{3}$ is -.397. Although it is not as well determined as $\hat{\alpha}_{3}$, it suggests that cutbacks in food consumption were undertaken even by those whose parents had shortfalls in the third quartile. In this regard, the effects of parental retirement experience predicted by the food equations are even more widespread. ${ }^{17}$

In the sample considered thus far, the largest shortfall is .797 , while the smallest is -1.03. One consideration that cannot be ignored is outliers. There are 9 main households that have shortfalls greater than .6, and 9 with shortfalls less than -.6. We removed 43 splitoff observations associated with these main households, the quartiles are re-defined, and Equations (7) to (10) are then re-estimated. There is still evidence of a negative consumption response by the splitoffs to large parental shortfalls. For Skinner's consumption, $\alpha_{4}$ has a point estimate of -.485 and is significant. Furthermore, $\hat{\alpha}_{3}$ is -.437 with a standard error of .272 . For food consumption, $\hat{\alpha}_{4}$ and $\hat{\alpha}_{3}$ are -.510 and -.558 respectively, and are significant at the 10 percent level. Thus, while the point estimates are quite sensitive to the treatment of outliers, the impact of shortfalls in parental post-retirement consumption is strongly negative for large shortfalls.

One explanation that is consistent with our findings is that large parental shortfalls represent "news" for both main households and splitoffs. Seeing a parent who is forced to make severe cutbacks in consumption could make an impression on children. The estimates

\footnotetext{
${ }^{17} \mathrm{We}$ also experimented with many variations of (10) to assess the robustness of the estimates. For example, we expanded the list of control variables to separately include parental permanent income and income of the splitoffs, but the results are extremely similar to those reported for $\alpha_{4}$ in Equation (10).
} 
for $\alpha_{3}$ and $\alpha_{4}$ suggest that splitoffs whose parents experienced large shortfalls begin to engage in belt-tightening of their own, even well in advance of retirement age. While the evidence is informal, it is consistent with some form of learning. Using data from the Health and Retirement Survey (HRS), Lusardi (2000) found that respondents whose parents suffered from health problems before dying are more likely to think about retirement. Furthermore, respondents are also more likely to plan for retirement if the financial situation of the older siblings is worse than their own financial situation. Our results suggest that not only do consumers simply plan, they actually take action by reducing consumption. Such evidence in support of the learning hypothesis is important because if this is indeed the behavior that is occurring, then children are not necessarily inclined to repeat the retirement experiences of their parents.

If the shortfalls in consumption are truly "news," and if in addition, there are operative transfers from parents to children, then an alternative explanation of the results could be shared budget constraints. If parents find that they have fewer resources than expected, the children might expect fewer transfers from them, and so they reduce their consumption. To explore this idea, we removed from the sample those who reported that they expected to receive an inheritance (a little over a fifth of the sample). We re-estimated all the specifications using this subsample. As we can see from Table $6, \hat{\alpha}_{3}$ and $\alpha_{4}$ remain significant. One reason why these estimates are so similar to the ones obtained from the full sample is that parents with large shortfalls are presumably also less likely to enable financial transfers to the children. Thus, splitoff cutbacks in consumption in the face of large parental consumption shortfalls appear not to be due to the possible loss of parental transfers per se.

Another implication of shared budget constraints is that children might increase "reverse transfers", i.e. financial transfers from children to their parents. Having a parent who has retired unprepared, and hence is in need of financial help, could at least in principle explain simultaneous reductions in the consumption of parents and children. But for this explanation to be able to account for the observed declines in child consumption, it would have to be the case that "reverse transfers" are quantitatively important. However, evidence indicates that these transfers are relatively small in the United States. The average transfer given by children to living parents or in-laws among the HRS respondents was only $\$ 264$ (or around one percent of median income), and less than 20 percent of the sample made reverse transfers. Thus, even though reverse transfers might account for some of the reduction in the consumption of the splitoffs, the estimated magnitude of reduction in consumption is too large to be due to reverse transfers alone. The result that children of parents who experienced pronounced shortfalls in consumption upon retirement tend themselves to consume less after 
their parents retired appears quite robust.

\section{Conclusion}

There are many channels through which the consumption of parents and children might be linked. Previous studies in the literature have focused on the intergenerational transmission of income. In this paper, we consider the possibility that parental effects unrelated to income - referred to as parental tastes in the analysis - could also be transmitted from one generation to the next. We find evidence for parental tastes in consumption of the splitoffs even after controlling for parental income. Over 10 percent of variations in tastes of the splitoffs are linked to parental tastes. ${ }^{18}$ Intergenerational influences arising from imitation and inherited habits cannot be ruled out.

The finding that tastes are correlated across generations would seem to suggest that impatient parents will have impatient kids, and so parents who save little for retirement will have children who also save little for retirement. On the contrary, we find a cutback in consumption of children whose parents experienced a shortfall in post-retirement consumption, so that while tastes might be inherited, children also learn from their parents' mistakes. This finding is important since there is much evidence suggesting that many households arrive at retirement unprepared, and must engage in retrenchment as a result. But if behavior can be shaped by education, policies that inform consumers about their financial vulnerabilities could lead to large increases in economic well-being. ${ }^{19}$ Our finding that parental misfortunes act like a "wake-up call" to children suggests that the learning channel is potentially open.

\footnotetext{
${ }^{18}$ Using a completely different approach, preliminary results of Charles and Hurst (2000) found a parental taste effect on wealth of very similar magnitude.

${ }^{19}$ From experimental evidence, the propensity of young children to delay their gratification can be influenced by the social milieu, including the choices and preferences displayed by role models (see, e.g., Bandura and Mischel [1965] and Mischel [1966, 1974]).
} 


\section{References}

[1] Abel, Andrew B. "Asset Prices under Habit Formation and Catching Up with the Joneses." American Economic Review 80 (May 1990): 38-42.

[2] Abowd,, John and David Card, "On the Covariance Structure of Earnings and Hours Changes", Econometrica, 57, (March 1989): 411-46.

[3] Altonji, Joseph and Thomas Dunn, "An Intergenerational Model of Wages, Hours and Earnings", National Bureau of Economic Research Working Paper no. 4950 (December 1994)

[4] Altonji, Joseph and Lewis Segal, "Small Sample Bias in GMM Estimation of Covariance Structures", Journal of Business and Economic Statistics, 14:3, (July 1996), 353-366.

[5] Altonji, Joseph, Hayashi, Fumio, and Kotlikoff, Laurence. "Is the Extended Family Altruistically Linked? Direct Tests Using Micro Data." American Economic Review 82 (December 1992): 1177-1198.

[6] Baker, Michael, "Growth Rate Heterogeneity and the Covariance Structure of Life-Cycle Earnings", Journal of Labor Economics, 15:2, (April 1997): 338-375.

[7] Bandura, Albert and Mischel, Walter. "Modification of Self-Imposed Delay of Reward Through Exposure to Live and Symbolic Models." Journal of Personality and Social Psychology 2 (November 1965): 698-703.

[8] Becker, Gary S. "A Theory of the Allocation of Time." Economic Journal 75 (1965): 493-517.

[9] Becker, Gary S. and Tomes, Nigel. "Human Capital and the Rise and Fall of Families." Journal of Labor Economics 4, pt. 2 (July 1986): S1-S39.

[10] Becker, Gary S. and Mulligan, Casey. "On the Endogenous Determination of Time Preference," Quarterly Journal of Economics, 1997.

[11] Behrman, Jere, and Taubman, Paul. "The Intergenerational Correlation Between Children's Adult Earnings and Their Parent's Income: Results from the Michigan Panel Survey of Income Dynamics." Review of Income and Wealth 36 (June 1990): 115-127.

[12] Bernheim, B. Douglas. "Do Households Appreciate Their Financial Vulnerabilities? An Analysis of Actions, Perceptions, and Public Policy." Tax Policy and Economic Growth, Washington DC, American Council for Capital Formation, 1995.

[13] Bernheim, B. Douglas, Shleifer, Andrei, and Summers, Lawrence. "The Strategic Bequest Motive." Journal of Political Economy 93 (December 1985): 1045-76.

[14] Bernheim, B. Douglas, Skinner, Jonathan and Weinberg, Steven. "What Accounts for the Variation in Retirement Wealth Among U.S. Households?" National Bureau of Economic Research Working Paper no. 6227 (October 1997).

[15] Browning, M. and A. Lusardi. "Household Saving: Micro Theories and Micro Facts", Journal of Economic Literature 34 (1996): 1797-1855.

[16] Charles, K. and Hurst, E. "The Correlation of Wealth Across Generations", manuscript in preparation, University of Chicago. 
[17] Campbell, John Y., Andrew W. Lo, and A. Craig Mackinlay. The Econometrics of Financial Markets (Princeton: Princeton University Press, 1997).

[18] Cox, Donald. "Motives for Private Income Transfers." Journal of Political Economy 95 (June 1987): 508-546.

[19] Cox, Donald "Intergenerational Transfers and Liquidity Constraints." Quarterly Journal of Economics 105 (February 1990): 187-217.

[20] Duesenberry, James S. Income, Saving and the Theory of Consumer Behavior (Princeton, N.J.: Harvard University Press, 1949).

[21] Hamermesh, Daniel S. "Consumption During Retirement: the Missing Link in the LifeCycle." Review of Economics and Statistics 66 (February 1984): 1-7.

[22] Leibenstein, Harvey. "Bandwagon, Snob and Veblen Effects in the Theory of Consumer's Demand." Quarterly Journal of Economics 64 (May 1950): 183-207.

[23] Lusardi, Anna. "Explaining Why do many Households Do not Save" mimeo, Dartmouth College, (2000).

[24] Mariger, Randall P. "A Life-Cycle Consumption Model with Liquidity Constraints: Theory and Empirical Results." Econometrica 55 (May 1987): 533-57.

[25] Mischel, Walter. "Theory and Research on the Antecedents of Self-Imposed Delay of Reward." In: B. A. Maher (ed.) Progress in Experimental Research vol. 3. San Diego, CA: Academic Press, 1966.

[26] Mischel, Walter. "Processes in Delay Gratification." In: L. Berkowitz (ed.) Advances in Experimental Social Psychology vol. 7. New York: Academic Press, 1974.

[27] Mulligan, Casey. Parental Priorities and Economic Inequality (Chicago: University of Chicago Press, 1997).

[28] Skinner, Jonathan. "A Superior Measure of Consumption from the Panel Study of Income Dynamics." Economics Letters, 23 (1987), pp. 213-216.

[29] Solon, Gary. "Intergenerational Income Mobility in the United States." American Economic Review 82 (June 1992): 393-408.

[30] Zimmerman, David J. "Regression Toward Mediocrity in Economic Stature." American Economic Review 82 (June 1992): 409-429. 
Table 1: Mobility of Income (top) and Consumption (bottom) Percent of splitoffs quintile by main household quintile

\begin{tabular}{|c|ccccc|c|}
\hline & \multicolumn{5}{|c|}{ Split-Offs } & Total \\
\hline Main households & 1 & 2 & 3 & 4 & 5 & $\mathrm{~N}$ \\
\hline 1 (lowest) & 40.00 & 24.79 & 16.06 & 10.99 & 8.17 & 355 \\
& 39.94 & 23.69 & 17.63 & 11.02 & 7.71 & 363 \\
& & & & & & \\
\hline 2 & 22.22 & 24.44 & 21.11 & 18.06 & 14.17 & 360 \\
& 24.38 & 26.59 & 17.45 & 19.67 & 11.91 & 361 \\
& & & & & & \\
\hline 3 & 18.44 & 19.88 & 21.61 & 23.34 & 16.71 & 347 \\
& 15.24 & 25.48 & 24.38 & 19.11 & 15.79 & 361 \\
& & & & & & \\
\hline 5 (highest) & 11.58 & 19.49 & 19.21 & 23.45 & 26.27 & 354 \\
& 13.26 & 15.47 & 24.03 & 24.03 & 23.20 & 362 \\
& & & & & & \\
\hline Total N & 7.65 & 11.33 & 22.10 & 24.36 & 34.56 & 353 \\
& & 8.86 & 16.34 & 26.32 & 41.27 & 361 \\
& 354 & 354 & 354 & 354 & 353 & 1769 \\
& 362 & 362 & 361 & 362 & 361 & 1808 \\
\hline
\end{tabular}


Table 2: Equally Weighted Estimation of the Intergenerational Model: Base Case, Split-Offs with 10+ years of data Splits

\begin{tabular}{|c|c|c|c|c|c|c|}
\hline & \multicolumn{2}{|c|}{ Skinner } & \multicolumn{2}{|c|}{ Total Food } & \multicolumn{2}{|c|}{$\frac{\text { Food Out }}{\text { Total Food }}$} \\
\hline & coef & s.e. & coef & s.e. & coef & s.e. \\
\hline$a$ & 0.850 & 0.024 & 0.588 & 0.023 & 0.129 & 0.006 \\
\hline$b$ & 0.871 & 0.025 & 0.552 & 0.025 & 0.062 & 0.008 \\
\hline$\phi$ & 0.479 & 0.015 & 0.450 & 0.019 & 0.513 & 0.025 \\
\hline$\gamma$ & 0.339 & 0.048 & 0.200 & 0.024 & 0.120 & 0.022 \\
\hline $\operatorname{var}\left[d_{i 0}\right]$ & 0.033 & 0.004 & 0.067 & 0.004 & 0.007 & 0.000 \\
\hline $\operatorname{var}\left[d_{i j}\right]$ & 0.030 & 0.004 & 0.063 & 0.004 & 0.010 & 0.000 \\
\hline $\operatorname{var}\left[y_{i 0}\right]$ & 0.211 & 0.007 & 0.222 & 0.010 & 0.199 & 0.010 \\
\hline $\operatorname{var}\left[y_{i j}\right]$ & 0.184 & 0.007 & 0.203 & 0.010 & 0.192 & 0.024 \\
\hline $\operatorname{var}\left[\epsilon_{i 0 t}\right]$ & 0.114 & 0.005 & 0.112 & 0.005 & 0.117 & 0.007 \\
\hline $\operatorname{var}\left[\epsilon_{i j t}\right]$ & 0.155 & 0.008 & 0.144 & 0.009 & 0.160 & 0.012 \\
\hline $\operatorname{var}\left[e_{i 0 t}\right]$ & 0.068 & 0.005 & 0.098 & 0.005 & 0.009 & 0.000 \\
\hline $\operatorname{var}\left[e_{i j t}\right]$ & 0.112 & 0.005 & 0.154 & 0.007 & 0.021 & 0.001 \\
\hline$\theta_{0}$ & -0.314 & 0.054 & -0.299 & 0.058 & -0.287 & 0.052 \\
\hline$\theta_{1}$ & -0.290 & 0.069 & -0.185 & 0.100 & -0.235 & 0.132 \\
\hline$\rho_{0}$ & 0.794 & 0.028 & 0.767 & 0.035 & 0.779 & 0.030 \\
\hline$\rho_{1}$ & 0.629 & 0.053 & 0.483 & 0.105 & 0.551 & 0.178 \\
\hline $\operatorname{var}\left[c_{i 0 t}\right]$ & & 0.253 & & 0.242 & & 0.020 \\
\hline $\operatorname{var}\left[c_{i j t}\right]$ & & 0.282 & & 0.279 & & 0.031 \\
\hline & \multicolumn{6}{|c|}{ Importance of Parental Effects } \\
\hline$\frac{\gamma^{2} \operatorname{var}\left[d_{i 0}\right]}{\operatorname{var}\left[d_{i j}\right]}$ & & 0.126 & & 0.043 & & 0.010 \\
\hline$\frac{\phi^{2} \operatorname{var}\left[y_{i 0}\right]}{\operatorname{var}\left[y_{i j}\right]}$ & & 0.200 & & 0.067 & & 0.001 \\
\hline$\frac{\gamma^{2} \operatorname{var}\left[d_{i 0}\right]+b^{2} \phi^{2} \operatorname{var}\left[y_{i 0}\right]}{\operatorname{var}\left[c_{i j t}\right]}$ & & 0.144 & & 0.059 & & 0.010 \\
\hline$\frac{\gamma^{2} \operatorname{var}\left[d_{i 0}\right]+b^{2} \phi^{2} \operatorname{var}\left[y_{i 0}\right]}{\operatorname{var}\left[c_{i j t}\right]-\operatorname{var}\left[e_{i j t}\right]}$ & & 0.239 & & 0.131 & & 0.028 \\
\hline
\end{tabular}


Table 3: Sensitivity Analysis (Skinner's Consumption)

\begin{tabular}{|c|c|c|c|c|c|c|}
\hline & \multicolumn{2}{|c|}{ Trimmed Outliers } & \multicolumn{2}{|c|}{ All Splits } & \multicolumn{2}{|c|}{ WLS } \\
\hline & coef & s.e. & coef & s.e. & coef & s.e. \\
\hline$a$ & 0.818 & 0.028 & 0.872 & 0.022 & 0.797 & 0.021 \\
\hline$b$ & 0.919 & 0.033 & 0.874 & 0.024 & 0.860 & 0.024 \\
\hline$\phi$ & 0.362 & 0.013 & 0.496 & 0.014 & 0.446 & 0.015 \\
\hline$\gamma$ & 0.325 & 0.043 & 0.379 & 0.049 & 0.263 & 0.032 \\
\hline $\operatorname{var}\left[d_{i 0}\right]$ & 0.037 & 0.005 & 0.031 & 0.004 & 0.045 & 0.004 \\
\hline $\operatorname{var}\left[d_{i j}\right]$ & 0.029 & 0.004 & 0.029 & 0.004 & 0.036 & 0.004 \\
\hline $\operatorname{var}\left[y_{i 0}\right]$ & 0.204 & 0.008 & 0.207 & 0.006 & 0.218 & 0.007 \\
\hline $\operatorname{var}\left[y_{i j}\right]$ & 0.132 & 0.005 & 0.184 & 0.007 & 0.172 & 0.007 \\
\hline $\operatorname{var}\left[\epsilon_{i 0 t}\right]$ & 0.113 & 0.005 & 0.117 & 0.006 & 0.107 & 0.005 \\
\hline $\operatorname{var}\left[\epsilon_{i j t}\right]$ & 0.142 & 0.008 & 0.164 & 0.008 & 0.147 & 0.008 \\
\hline $\operatorname{var}\left[e_{i 0 t}\right]$ & 0.065 & 0.004 & 0.064 & 0.004 & 0.056 & 0.003 \\
\hline $\operatorname{var}\left[e_{i j t}\right]$ & 0.100 & 0.004 & 0.125 & 0.005 & 0.092 & 0.004 \\
\hline$\theta_{0}$ & -0.308 & 0.057 & -0.357 & 0.054 & -0.437 & 0.054 \\
\hline$\theta_{1}$ & -0.262 & 0.071 & -0.285 & 0.064 & -0.402 & 0.065 \\
\hline$\rho_{0}$ & 0.782 & 0.031 & 0.802 & 0.027 & 0.846 & 0.027 \\
\hline$\rho_{1}$ & 0.609 & 0.055 & 0.618 & 0.050 & 0.725 & 0.045 \\
\hline $\operatorname{var}\left[c_{i 0 t}\right]$ & & 0.238 & & 0.253 & & 0.253 \\
\hline $\operatorname{var}\left[c_{i j t}\right]$ & & 0.240 & & 0.294 & & 0.282 \\
\hline & \multicolumn{6}{|c|}{ Importance of Parental Effects } \\
\hline$\frac{\gamma^{2} \operatorname{var}\left[d_{i 0}\right]}{\operatorname{var}\left[d_{i j}\right]}$ & & 0.135 & & 0.154 & & 0.086 \\
\hline$\frac{\phi^{2} \operatorname{var}\left[y_{i 0}\right]}{\operatorname{var}\left[y_{i j}\right]}$ & & 0.171 & & 0.214 & & 0.186 \\
\hline$\frac{\gamma^{2} \operatorname{var}\left[d_{i 0} 0\right]+b^{2} \phi^{2} \operatorname{var}\left[y_{i 0}\right]}{\operatorname{var}\left[c_{i j t}\right]}$ & & 0.110 & & 0.147 & & 0.125 \\
\hline$\frac{\gamma^{2} \operatorname{var}\left[d_{i 0}\right]+b^{2} \phi^{2} \operatorname{var}\left[y_{i j}\right]}{\operatorname{var}\left[c_{i j j}\right]-\operatorname{var}\left[e_{i j t}\right]}$ & & 0.189 & & 0.258 & & 0.216 \\
\hline
\end{tabular}


Table 4: Estimation of the Intragenerational Model

\begin{tabular}{|c|c|c|c|c|c|c|}
\hline & \multicolumn{2}{|c|}{ Skinner } & \multicolumn{2}{|c|}{ Total Food } & \multicolumn{2}{|c|}{$\frac{\text { Food Out }}{\text { Total Food }}$} \\
\hline & coef & s.e. & coef & s.e. & coef & s.e. \\
\hline$a$ & 0.753 & 0.036 & 0.593 & 0.040 & 0.052 & 0.013 \\
\hline$b$ & 0.794 & 0.040 & 0.514 & 0.040 & 0.057 & 0.012 \\
\hline$\phi$ & 0.463 & 0.025 & 0.611 & 0.044 & 0.480 & 0.108 \\
\hline$\gamma$ & 0.453 & 0.076 & 0.378 & 0.096 & 0.125 & 0.047 \\
\hline $\operatorname{var}\left[d_{i 0}\right]$ & 0.030 & 0.005 & 0.030 & 0.005 & 0.006 & 0.001 \\
\hline $\operatorname{var}\left[d_{i j}\right]$ & 0.021 & 0.005 & 0.034 & 0.005 & 0.005 & 0.000 \\
\hline $\operatorname{var}\left[y_{i 0}\right]$ & 0.179 & 0.010 & 0.157 & 0.011 & 0.199 & 0.046 \\
\hline $\operatorname{var}\left[y_{i j}\right]$ & 0.139 & 0.010 & 0.175 & 0.015 & 0.183 & 0.037 \\
\hline $\operatorname{var}\left[\epsilon_{i 0 t}\right]$ & 0.120 & 0.012 & 0.195 & 0.017 & 0.176 & 0.041 \\
\hline $\operatorname{var}\left[\epsilon_{i j t}\right]$ & 0.153 & 0.025 & 0.201 & 0.015 & 0.195 & 0.034 \\
\hline $\operatorname{var}\left[e_{i 0 t}\right]$ & 0.120 & 0.005 & 0.194 & 0.013 & 0.022 & 0.001 \\
\hline $\operatorname{var}\left[e_{i j t}\right]$ & 0.124 & 0.009 & 0.215 & 0.013 & 0.027 & 0.001 \\
\hline$\theta_{0}$ & -0.602 & 0.304 & -0.741 & 0.245 & -0.453 & 2.323 \\
\hline$\theta_{1}$ & -0.838 & 0.369 & -0.563 & 0.574 & -0.361 & 2.181 \\
\hline$\rho_{0}$ & 0.749 & 0.271 & 0.897 & 0.164 & 0.505 & 2.522 \\
\hline$\rho_{1}$ & 0.956 & 0.188 & 0.645 & 0.558 & 0.410 & 2.320 \\
\hline $\operatorname{var}\left[c_{i 0 t}\right]$ & & 0.281 & & 0.279 & & 0.029 \\
\hline $\operatorname{var}\left[c_{i j t}\right]$ & & 0.297 & & 0.296 & & 0.033 \\
\hline & \multicolumn{6}{|c|}{ Importance of Parental Effects } \\
\hline$\frac{\gamma^{2} \operatorname{var}\left[d_{i 0}\right]}{\operatorname{var}\left[d_{i j}\right]}$ & & 0.296 & & 0.126 & & 0.019 \\
\hline$\frac{\left.\phi^{2} \operatorname{var}\left[y_{i}\right]\right]}{\operatorname{var}\left[y_{i j}\right]}$ & & 0.174 & & 0.088 & & 0.001 \\
\hline$\frac{\gamma^{2} \operatorname{var}\left[d_{i i}\right]+b^{2} \phi^{2} \operatorname{var}\left[y_{i 0}\right]}{\operatorname{var}\left[c_{i j t}\right]}$ & & 0.102 & & 0.067 & & 0.007 \\
\hline$\frac{\gamma^{2} \operatorname{var}\left[d_{i 0}\right]+b^{2} \phi^{2} \operatorname{var}\left[y_{i 0}\right]}{\left.\operatorname{var}\left[c_{i j i}\right]-\operatorname{var}\left[e_{i j t}\right]\right]}$ & & 0.279 & & 0.246 & & 0.043 \\
\hline
\end{tabular}


Table 5: Equally Weighted Estimation of the Intergenerational Model: Controlling for Retirement

\begin{tabular}{|c|c|c|c|c|c|c|}
\hline & \multicolumn{2}{|c|}{ Ret. dummy } & \multicolumn{2}{|c|}{ Never retire } & \multicolumn{2}{|c|}{ Retire } \\
\hline & coef & s.e. & coef & s.e. & coef & s.e. \\
\hline$a$ & 0.849 & 0.024 & 0.862 & 0.038 & 0.842 & 0.030 \\
\hline$b$ & 0.871 & 0.025 & 0.908 & 0.043 & 0.848 & 0.031 \\
\hline$\phi$ & 0.479 & 0.015 & 0.463 & 0.022 & 0.490 & 0.021 \\
\hline$\gamma$ & 0.336 & 0.048 & 0.314 & 0.118 & 0.340 & 0.051 \\
\hline $\operatorname{var}\left[d_{i 0}\right]$ & 0.033 & 0.004 & 0.018 & 0.006 & 0.045 & 0.006 \\
\hline $\operatorname{var}\left[d_{i j}\right]$ & 0.030 & 0.004 & 0.031 & 0.007 & 0.029 & 0.005 \\
\hline $\operatorname{var}\left[y_{i 0}\right]$ & 0.211 & 0.007 & 0.194 & 0.011 & 0.223 & 0.009 \\
\hline $\operatorname{var}\left[y_{i j}\right]$ & 0.184 & 0.007 & 0.165 & 0.009 & 0.198 & 0.010 \\
\hline $\operatorname{var}\left[\epsilon_{i 0 t}\right]$ & 0.114 & 0.005 & 0.107 & 0.008 & 0.120 & 0.007 \\
\hline $\operatorname{var}\left[\epsilon_{i j t}\right]$ & 0.155 & 0.008 & 0.172 & 0.013 & 0.142 & 0.010 \\
\hline $\operatorname{var}\left[e_{i 0 t}\right]$ & 0.068 & 0.005 & 0.048 & 0.003 & 0.085 & 0.008 \\
\hline $\operatorname{var}\left[e_{i j t}\right]$ & 0.113 & 0.005 & 0.113 & 0.007 & 0.112 & 0.008 \\
\hline$\theta_{0}$ & -0.314 & 0.054 & -0.285 & 0.080 & -0.336 & 0.074 \\
\hline$\theta_{1}$ & -0.289 & 0.069 & -0.253 & 0.094 & -0.314 & 0.100 \\
\hline$\rho_{0}$ & 0.794 & 0.028 & 0.781 & 0.041 & 0.805 & 0.037 \\
\hline$\rho_{1}$ & 0.629 & 0.053 & 0.577 & 0.080 & 0.665 & 0.072 \\
\hline $\operatorname{var}\left[c_{i 0 t}\right]$ & & 0.253 & & 0.211 & & 0.288 \\
\hline $\operatorname{var}\left[c_{i j t}\right]$ & & 0.282 & & 0.280 & & 0.284 \\
\hline & \multicolumn{6}{|c|}{ Importance of Parental Effects } \\
\hline$\frac{\gamma^{2} \operatorname{var}\left[d_{i 0}\right]}{\operatorname{var}\left[d_{i j}\right]}$ & & 0.126 & & 0.099 & & 0.147 \\
\hline$\frac{\phi^{2} \operatorname{var}\left[y_{i 0}\right]}{\operatorname{var}\left[y_{i j}\right]}$ & & 0.200 & & 0.209 & & 0.195 \\
\hline$\frac{\gamma^{2} \operatorname{var}\left[d_{i 0}\right]+b^{2} \phi^{2} \operatorname{var}\left[y_{i 0}\right]}{\operatorname{var}\left[c_{i j t}\right]}$ & & 0.144 & & 0.136 & & 0.150 \\
\hline$\frac{\gamma^{2} \operatorname{var}\left[d_{i 0}\right]+b^{2} \phi^{2} \operatorname{var}\left[y_{i 0}\right]}{\operatorname{var}\left[c_{i j t}\right]-\operatorname{var}\left[e_{i j t}\right]}$ & & 0.239 & & 0.227 & & 0.248 \\
\hline
\end{tabular}


Table 6: Effects of Parental Retirement on Consumption of the Splitoffs (standard errors in parentheses)

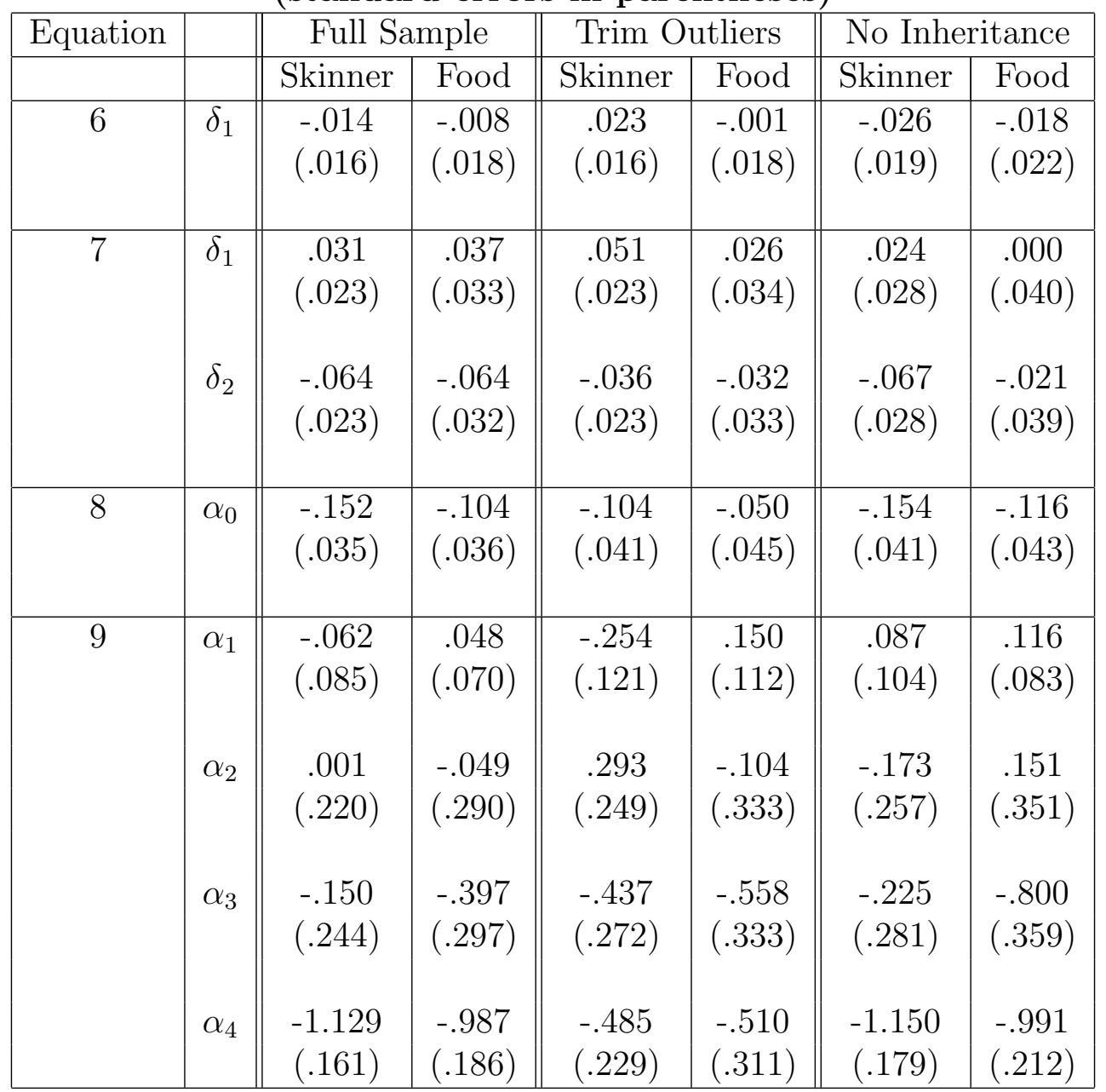

$\mathrm{Eq}(6): \log C_{i j, t}=g_{i j}+\delta_{0}+\delta_{1} D_{i, t}^{R E T}+\beta^{\prime} X_{i j, t}+e_{i j, t}$

$\mathrm{Eq}(7): \log C_{i j, t}=g_{i j}+\delta_{0}+\delta_{1} D_{i, t}^{R E T}+\delta_{2}\left[D_{i}^{S h o r t+} \cdot D_{i, t}^{R E T}\right]+\beta^{\prime} X_{i j, t}+e_{i j, t}$

$\mathrm{Eq}(8): \log C_{i j, t}=g_{i j}+\delta_{0}+\alpha_{0}\left[\right.$ Short $\left._{i} \cdot D_{i, t}^{R E T}\right]+\beta^{\prime} X_{i j, t}+e_{i j, t}$

$\mathrm{Eq}(9): \log C_{i j, t}=g_{i j}+\delta_{0}+\sum_{k=1}^{4} \delta_{k} D_{i, t}^{\text {Quartile }}(k)+\sum_{k=1}^{4} \alpha_{k}\left[\operatorname{Short}_{i} \cdot D_{i, t}^{\text {Quartile }}(k)\right]+\beta^{\prime} X_{i j, t}+e_{i j, t}$

Short $i$ is post retirement shortfall in consumption of main household $i$.

$D_{i, t}^{R E T}=1$ if main household $i$ has retired in period $t$.

$D_{i}^{S h o r t+}=1$ if main household $i$ has retired in period $t$, and his shortfall is positive.

$D_{i}^{\text {Quartile }}(k)=1$ if main household $i$ 's shortfall is in the $k^{\text {th }}$ quartile and he has retired at time $t$. 
Table A: Descriptive Statistics

\begin{tabular}{|c|c|c|c|c|}
\hline $\begin{array}{l}\text { No. of children } \\
\text { per main household }\end{array}$ & $\begin{array}{l}\text { Sample } \\
\text { Size }\end{array}$ & $\begin{array}{c}\text { Percent of } \\
\text { sample }\end{array}$ & $\begin{array}{l}\text { Number of } \\
\text { splitoffs }\end{array}$ & $\begin{array}{l}\text { Percent of } \\
\text { sample }\end{array}$ \\
\hline 1 & 332 & 39.43 & 332 & 18.36 \\
\hline 2 & 255 & 30.29 & 510 & 28.21 \\
\hline 3 & 137 & 16.27 & 411 & 22.73 \\
\hline 4 & 70 & 8.31 & 280 & 15.49 \\
\hline 5 & 31 & 3.68 & 155 & 8.57 \\
\hline 6 & 6 & .71 & 36 & 1.99 \\
\hline 7 & 6 & .71 & 42 & 2.32 \\
\hline 8 & 4 & .48 & 32 & 1.77 \\
\hline 10 & 1 & .12 & 10 & .55 \\
\hline \multirow[t]{3}{*}{ Total } & 842 & 100 & \multirow{2}{*}{\multicolumn{2}{|c|}{ Split-offs Households }} \\
\hline & \multicolumn{2}{|c|}{ Main Households } & & \\
\hline & \multicolumn{4}{|c|}{ Full Sample } \\
\hline No. of time series obs & \multicolumn{2}{|r|}{20.92} & & 11.26 \\
\hline Years of consumption after retirement & \multirow{2}{*}{\multicolumn{2}{|c|}{$\begin{array}{c}2.77 \\
60426\end{array}$}} & & 0.12 \\
\hline Average income & & & & 46,167 \\
\hline Average consumption & \multicolumn{2}{|r|}{30,661} & & 28,851 \\
\hline Family Size & \multicolumn{2}{|r|}{3.199} & & 2.646 \\
\hline Age in 1992 & \multicolumn{2}{|r|}{62.9} & & 35.5 \\
\hline Percent retired by 1992 & \multicolumn{2}{|r|}{40.9} & & 3.03 \\
\hline Percent Married & \multicolumn{2}{|r|}{81.5} & & 65.6 \\
\hline Percent single female head & \multicolumn{2}{|r|}{14.5} & & 16.9 \\
\hline Age splitoff left home & \multicolumn{2}{|r|}{-} & & 22.9 \\
\hline & \multicolumn{4}{|c|}{ Retirement Sample } \\
\hline Sample Size & \multirow{2}{*}{\multicolumn{2}{|c|}{281}} & & 534 \\
\hline No. Years before main retired & & & & 8.5 \\
\hline No. Years after main retired & \multicolumn{2}{|r|}{$\begin{array}{c}16.9 \\
8.1\end{array}$} & & 5.4 \\
\hline Age in 1992 & \multicolumn{2}{|r|}{70.1} & & 39.4 \\
\hline Age when main retired & \multicolumn{2}{|r|}{63.8} & & 33.7 \\
\hline & \multicolumn{2}{|c|}{ Income } & \multicolumn{2}{|c|}{ "Consumption } \\
\hline & Before & After & Before & After \\
\hline Parents & 61,109 & 35,263 & 28,671 & 25,044 \\
\hline Splitoffs & 47,319 & 63,608 & 22,702 & 30,493 \\
\hline Shortfall & \multicolumn{2}{|c|}{ Skinner } & \multicolumn{2}{|c|}{ Food } \\
\hline mean & & .123 & & .218 \\
\hline $\max$ & & .797 & & .860 \\
\hline $\min$ & & -1.030 & & -1.122 \\
\hline 25 pct & & -.020 & & .105 \\
\hline median & & .159 & & .252 \\
\hline 75 pct & & .317 & & .403 \\
\hline
\end{tabular}




\section{Appendix B}

The 10 moments based on contemporaneous covariances are:

$$
\begin{aligned}
\text { A1. } \quad \operatorname{var}\left[c_{i 0 t}\right] & =a^{2} \operatorname{var}\left[y_{i 0}\right]+\operatorname{var}\left[d_{i 0}\right]+\operatorname{var}\left[e_{i 0 t}\right], \\
\text { A2. } \quad \operatorname{var}\left[c_{i j t}\right] & =b^{2} \operatorname{var}\left[y_{i j}\right]+\operatorname{var}\left[d_{i j}\right]+\operatorname{var}\left[e_{i j t}\right], \\
\text { A3. } \quad \operatorname{cov}\left[c_{i 0 t}, c_{i j t}\right] & =\operatorname{cov}\left[d_{i 0}, d_{i j}\right]+\operatorname{abcov}\left[y_{i 0}, y_{i j}\right], \\
\text { A4. } \quad \operatorname{var}\left[y_{i 0 t}\right] & =\operatorname{var}\left[y_{i 0}\right]+\operatorname{var}\left(z_{i 0 t}\right)(0), \\
\text { A5. } \quad \operatorname{var}\left[y_{i j t}\right] & =\operatorname{var}\left[y_{i j}\right]+\operatorname{var}\left[z_{i j t}(0)\right], \\
\text { A6. } \quad \operatorname{cov}\left[y_{i 0, t}, y_{i j, t}\right] & =\operatorname{cov}\left[y_{i 0}, y_{i j}\right], \\
A 7 . \quad \operatorname{cov}\left[c_{i 0, t}, y_{i 0, t}\right] & =a \operatorname{var}\left[y_{i 0}\right], \\
A 8 . \quad \operatorname{cov}\left[c_{i 0, t}, y_{i j, t}\right] & =a \operatorname{cov}\left[y_{i 0}, y_{i j}\right], \\
A 9 . \quad \operatorname{cov}\left[c_{i j, t}, y_{i 0, t}\right] & =b \operatorname{cov}\left[y_{i j}, y_{i 0}\right], \\
A 10 . \quad \operatorname{cov}\left[c_{i j, t}, y_{i j, t}\right] & =b \operatorname{var}\left[y_{i j}\right],
\end{aligned}
$$

For $k>0$, we have the following 16 autocovariances:

$$
\begin{aligned}
& \text { B1. } \operatorname{cov}\left[c_{i 0 t}, y_{i 0, t-k}\right]=a \operatorname{var}\left[y_{i 0}\right], \\
& \text { B2. } \operatorname{cov}\left[c_{i j t}, y_{i 0, t-k}\right]=b \operatorname{cov}\left[y_{i j}, y_{i 0}\right] \text {, } \\
& \text { B3. } \operatorname{cov}\left[c_{i j t}, y_{i j, t-k}\right]=\operatorname{bvar}\left[y_{i j}\right] \text {, } \\
& \text { B4. } \operatorname{cov}\left[c_{i j t}, c_{i j, t-k}\right]=\operatorname{var}\left(d_{i j}\right]+b^{2} \operatorname{var}\left[y_{i j}\right] \text {, } \\
& \text { B5. } \operatorname{cov}\left[c_{i 0, t}, c_{i 0, t-k}\right]=\operatorname{var}\left(d_{i 0}\right]+a^{2} \operatorname{var}\left[y_{i 0}\right], \\
& \text { B6. } \operatorname{cov}\left[c_{i 0, t}, c_{i j, t-k}\right]=\operatorname{cov}\left[d_{i 0}, d_{i j}\right]+a b \operatorname{cov}\left[y_{i 0}, y_{i j}\right] \text {, } \\
& \text { B7. } \operatorname{cov}\left[c_{i 0, t-k}, c_{i j, t}\right]=\operatorname{cov}\left[d_{i 0}, d_{i j}\right]+a b \operatorname{cov}\left[y_{i 0}, y_{i j}\right] \text {, } \\
& \text { B8. } \operatorname{cov}\left[c_{i 0, t}, y_{i j, t-k}\right]=a \operatorname{cov}\left[y_{i 0}, y_{i j}\right] \text {, } \\
& \text { B9. } \operatorname{cov}\left[c_{i 0, t-k}, y_{i 0, t}\right]=\operatorname{avar}\left[y_{i 0}\right], \\
& \text { B10. } \operatorname{cov}\left[c_{i 0, t-k}, y_{i j, t-k}\right]=a \operatorname{cov}\left[y_{i 0}, y_{i j}\right] \text {, } \\
& \text { B11. } \operatorname{cov}\left[c_{i j, t-k}, y_{i 0, t}\right]=b \operatorname{cov}\left[y_{i j}, y_{i 0}\right] \text {, } \\
& \text { B12. } \operatorname{cov}\left[c_{i j, t-k}, y_{i j, t}=b \operatorname{var}\left[y_{i j}\right]\right. \text {, } \\
& \text { B13. } \operatorname{cov}\left[y_{i 0, t}, y_{i j, t-k}\right]=\operatorname{cov}\left[y_{i 0}, y_{i j}\right] \text {, } \\
& \text { B14. } \operatorname{cov}\left[y_{i 0, t-k}, y_{i j, t}\right]=\operatorname{cov}\left[y_{i 0}, y_{i j}\right] \text {, } \\
& \text { B15. } \operatorname{cov}\left[y_{i 0 t}, y_{i 0, t-k}\right]=\operatorname{var}\left[y_{i 0}\right]+\rho_{0}^{k-1} \operatorname{var}\left[z_{i 0 t}\right](1) \text {, } \\
& \text { B16. } \operatorname{cov}\left[y_{i j t}, y_{i j, t-k}\right]=\operatorname{var}\left[y_{i j}\right]+\rho_{1}^{k-1} \operatorname{var}\left[z_{i j t}\right](1) \text {, } \\
& \text { with } \quad \operatorname{var}\left[d_{i j}\right]=\gamma^{2} \operatorname{var}\left[d_{i 0}\right]+\operatorname{var}\left[v_{i j}\right] \text {, } \\
& \operatorname{var}\left[y_{i j}\right] \quad=\phi^{2} \operatorname{var}\left[y_{i 0}\right]+\operatorname{var}\left[u_{i j}\right] \\
& \operatorname{cov}\left[d_{i o}, d_{i j}\right] \quad=\gamma \operatorname{var}\left[d_{i o}\right] \\
& \operatorname{cov}\left[y_{i o}, y_{i j}\right] \quad=\phi \operatorname{var}\left[y_{i o}\right] \\
& \operatorname{var}\left[z_{i 0 t}\right](0)=\sigma_{\epsilon_{0}}^{2}\left(1+\left(\rho_{0}+\theta_{0}\right)^{2} /\left(1-\rho_{0}^{2}\right)\right), \\
& \operatorname{var}\left[z_{i j t}\right](0)=\sigma_{\epsilon_{j}}^{2}\left(1+\left(\rho_{j}+\theta_{j}\right)^{2} /\left(1-\rho_{j}^{2}\right)\right), \\
& \operatorname{var}\left[z_{i 0 t}\right](1)=\sigma_{\epsilon_{0}}^{2}\left(\left(\rho_{0}+\theta_{0}\right)+\left(\rho_{0}+\theta_{0}\right)^{2} \rho_{0} /\left(1-\rho_{0}^{2}\right)\right) \text {, } \\
& \operatorname{var}\left[z_{i j t}\right](1)=\sigma_{\epsilon_{j}}^{2}\left(\left(\rho_{j}+\theta_{j}\right)+\left(\rho_{j}+\theta_{j}\right)^{2} \rho_{j} /\left(1-\rho_{j}^{2}\right)\right)
\end{aligned}
$$

Recall that consumption and income are regression residuals from a first step regression with time dummies and are mean zero for any period. Thus, as an example, var $\left[c_{i 0 t}\right]$ can be 
estimated as follows:

$$
\operatorname{var}\left[c_{i 0, t}\right]=\frac{1}{N T} \sum_{i=1}^{N_{t}} \sum_{t=1}^{T} c_{i 0, t}^{2},
$$

where $N=\sum_{t=1}^{T} N_{t}, N_{t}$ is the number of main households for which consumption data are available in period $t$. Likewise, $\operatorname{cov}\left[c_{i j, t}, c_{i j, t-1}\right]$ is replaced by

$$
\operatorname{cov}\left[c_{i 0, t}, c_{i j, t-1}\right]=\frac{1}{N T} \sum_{i=1}^{N_{t}} \sum_{t=1}^{T} \sum_{j=1}^{K_{i t}} c_{i 0, t} c_{i j, t-1},
$$

where $K_{i t}$ is the number of splitoffs associated with main household $i$ at time $t$, and $N=$ $\sum_{i} \sum_{t} K_{i t} N_{t}$ is now the number of observations for which consumption of the main household and lagged consumption of the splitoffs are both available.

\section{Notes on Skinner's measure of consumption}

Aside from the usual problems of mismeasurement of consumption, the PSID unfortunately provides only three elements of consumption. These are food consumed at home, food consumed away from home, and the value of food stamps received. Since our model pertains to total consumption, we would prefer to have information on all elements of consumption. Even though this information is not available, there is a way to proxy for total consumption, using just the consumption elements available in the PSID. Jonathan Skinner (Skinner 1987) proposes a technique that relies on a linear regression of total consumption taken from the Consumer Expenditure Survey (CEX) on consumption elements available in the PSID, such as food at home, food consumed away from home, the house value, rent, utility payments, and the number of automobiles. The regression, which is performed for the years 1972/73 and 1983, yields a set of coefficients which can then be used for other years to compute an estimate of total consumption. They appear to be very stable over time, which Skinner shows by predicting 1983 consumption using the coefficients estimated from the 1972/73 regression. The correlation between predicted values using either set of coefficients exceeds 0.98 regardless of the precise specification used. Using only food at home, food away from home, rent, and the house value in a regression yields an $\bar{R}^{2}$ of 0.9724 for $1972 / 73$, which hardly increases when adding utility payments and automobiles. The problem with including the other elements for our purposes is that utility payments were last asked in the 1987 survey while the number of automobiles per family is last reported in the 1986 survey. However, since the increase in predictive power through the use of these additional elements is small in any case, we construct total consumption measures using Skinner's estimated coefficients from the specification that only includes the four basic elements. 